\title{
Avaliação do desempenho operacional de uma estação de tratamento de lixiviado de aterro sanitário
}

Neste estudo foi realizada a avaliação do desempenho da estação de tratamento de lixiviados do aterro sanitário do município de Lages/SC. O sistema de tratamento é composto por uma lagoa anaeróbia, seguida de duas lagoas facultativas, duas lagoas aeradas, tratamento físico-químico baseado em coagulação e floculação, duas lagoas de decantação, desinfecção e posterior descarte no corpo receptor. Foram realizadas 10 coletas de efluente, em 9 pontos de amostragem distintos. Para cada amostra foi determinada a concentração de cloretos, cloro residual livre, coliformes fecais, cor, demanda bioquímica de oxigênio, ferro total, demanda química de oxigênio, fósforo total, nitrogênio amoniacal, oxigênio dissolvido, pH, sólidos dissolvidos totais, sólidos fixos totais, sólidos sedimentáveis totais, sólidos suspensos totais, sólidos totais, sólidos voláteis totais, sulfeto e turbidez. Para os parâmetros citados pela Resolução do Conselho Nacional do Meio Ambiente no 430/2011 e pela Lei do Estado de Santa Catarina no 14.675/2009, os resultados obtidos foram comparados com os limites estabelecidos. Com exceção do nitrogênio amoniacal, todos os parâmetros apresentaram-se em conformidade com o exigido pelas legislações supracitadas. A execução deste trabalho pode auxiliar na identificação de oportunidades de melhorias e alternativas para a operação da estação de tratamento de efluentes de aterros sanitários em outros municípios.

\section{Evaluation of the operational performance of a landfill leachate treatment plant}

\begin{abstract}
In this study, the operational performance of the leachate treatment plant of the sanitary landfill of the municipality of Lages/SC was evaluated. The treatment system consists of an anaerobic pond, followed by two facultative ponds, two aerated ponds, physical-chemical treatment based on coagulation and flocculation, two decantation ponds, disinfection and subsequent disposal in the receiving water body. Ten effluent samples were collected at 9 different sampling points. For each sample was determinate the concentration of chlorides, free residual chlorine, fecal coliforms, color, biochemical oxygen demand, total iron, chemical oxygen demand, total phosphorus, ammoniacal nitrogen, dissolved oxygen, $\mathrm{pH}$, total dissolved solids, total fixed solids, total settling solids, total suspended solids, total solids, total volatile solids, sulfide and turbidity. For the parameters cited by the Resolution of the National Environmental Council $n=430 / 2011$ and by the Law of the State of Santa Catarina no 14.675/2009, the results obtained were compared with the established limits. Except for ammoniacal nitrogen, all parameters were in accordance with the requirements of the abovementioned legislation. The accomplishment of this work can assist the landfill managers to identify opportunities for improvements and alternatives for the effluent treatment plant operation.
\end{abstract}

Keywords: Solid waste; Stabilization ponds; Landfill.

Topic: Engenharia Sanitária

Reviewed anonymously in the process of blind peer
Received: 10/12/2019

Approved: $14 / 01 / 2020$
Ricardo Mancilio Vieira

Universidade do Estado de Santa Catarina, Brasil

http://lattes.cnpq.br/3144564954577864

ricardovieiraea@hotmail.com

Diego Hoefling Souza (id)

Universidade do Estado de Santa Catarina, Brasil

http://lattes.cnpq.br/6023870279123785

http://orcid.org/0000-0002-2186-2078

diego.hoefling@gmail.com

Júlia Nercolini Göde (iD)

Universidade do Estado de Santa Catarina, Brasil

http://lattes.cnpq.br/8172218911058696

http://orcid.org/0000-0003-4336-0877

julianercolini@hotmail.com

\author{
Bruno Dalledone Bittar \\ Universidade do Estado de Santa Catarina, Brasil \\ http://lattes.cnpq.br/3430091355686573 \\ bdbittar@gmail.com \\ Viviane Trevisan (iD \\ Universidade do Estado de Santa Catarina, Brasil \\ http://lattes.cnpq.br/7784298111720472 \\ http://orcid.org/0000-0003-4826-0269 \\ viviane.trevisan@udesc.br \\ Everton Skoronski (it) \\ Universidade do Estado de Santa Catarina, Brasil \\ http://lattes.cnpq.br/0183604664567378 \\ http://orcid.org/0000-0002-8554-8272 \\ skoronski@cav.udesc.br
}

Referencing this:

VIEIRA, R. M.; SOUZA, D. H.; GODE, J. N.; BITTAR, B. D.; TREVISAN, V.; SKORONSKI, E.. Avaliação do desempenho operacional de uma estação de tratamento de lixiviado de aterro sanitário. Revista lbero Americana de Ciências Ambientais, v.11, n.1, p.131-145, 2020. DOI: http://doi.org/10.6008/CBPC2179-6858.2020.001.0013 


\section{INTRODUÇÃO}

O constante aumento na geração de resíduos sólidos urbanos é um tema bastante pertinente atualmente. Em 2013, no Brasil, foram recolhidas diariamente mais de 180.000 toneladas de resíduos sólidos municipais e os lixões ainda se fazem presentes em milhares de cidades (BESEN et al., 2016). Atualmente a destinação, mais empregada e ambientalmente adequada, para os resíduos sólidos urbanos é o uso de aterros sanitários (AHARONI et al., 2017; HAN et al., 2016). No entanto, a disposição inadequada destes resíduos pode dar origem a um lixiviado constituído de uma complexa combinação de poluentes com características toxicológicas persistentes, além de diferentes contaminantes orgânicos e inorgânicos recalcitrantes, tais como ácidos húmicos e fúlvicos, hidrocarbonetos policíclicos aromáticos, pesticidas, elementos-traço e altos níveis de nitrogênio amoniacal (LI et al., 2014; REGADío et al., 2012).

As concentrações dos compostos químicos que compõem o lixiviado podem variar de acordo com as características dos resíduos, idade do aterro, condições ambientais, modo operacional do aterro e mecanismo de decomposição da matéria orgânica, o que torna o tratamento de lixiviado de aterro sanitário difícil de ser padronizado (RENOU et al., 2008; MORAVIA et al., 2013).

Diversos estudos foram realizados combinando processos de tratamento para remover os compostos químicos que compõem o lixiviado de aterro, obtendo resultados satisfatórios para os parâmetros avaliados. Foi estudado processos constituídos por lagoas anaeróbias, lodos ativados e lagoas facultativas; Moravia (2013) utilizou processos oxidativos avançados combinados com membranas para tratamento de lixiviados. Já outro autor pesquisou o uso de filtros anaeróbios seguidos de banhados construídos; um outro autor estudou o uso de banhados construídos; já foi analisado o uso de fotocatálise heterogêneas combinada com lodos ativados e avaliaram o uso de coagulantes químicos para o tratamento de lixiviados de aterros.

Mesmo em aterro sanitários impermeabilizados existem riscos ao ambiente, uma vez que, se a mesma não for bem executada, pode possibilitar a percolação do lixiviado, contaminando o solo e as águas subterrâneas (SIZIRICl et al., 2015). Além disso, de modo a minimizar os danos às águas superficiais, o lixiviado gerado no aterro deve ser coletado e tratado adequadamente (DIA et al., 2018).

Diante disto, e com a crescente exigência legal nos padrões para descarte de efluentes e resíduos fica evidente a necessidade de acompanhamento da eficiência de sistemas de tratamentos utilizados em aterros sanitários, de modo que o efluente tratado apresente satisfatória qualidade físico-química e microbiológica, sem prejudicar a saúde da população e danificar as características ambientais da região, ao contrário do que já foi observado em muitos países em desenvolvimento (AKINBILE, 2012; BHALLA et al., 2012; SMAHI et al., 2013). Neste contexto, o presente estudo teve como objetivo caracterizar o lixiviado e avaliar eficiência da estação de tratamento de efluentes do aterro sanitário do município de Lages/SC.

\section{MATERIAIS E MÉTODOS}

\section{Descrição do aterro sanitário de Lages-SC e de sua estação de tratamento de efluentes}

O Aterro Sanitário do município de Lages-SC está situado na margem esquerda da BR-282 sentido 
Lages/Florianópolis - SC (27 44' 77" S e 50 09’ 93” O). O município apresenta um tipo climático CFB Temperado (mesotérmico úmido com verões amenos), conforme a classificação de Köppen. As temperaturas médias anuais situam-se entre 15 e $16 \stackrel{\circ}{ } \mathrm{C}$ e a precipitação pluviométrica média anual varia entre 1.500 e $1.600 \mathrm{~mm}$. No período de inverno as temperaturas podem atingir valores negativos, com médias mensais entre 6 e 8 으 (EMBRAPA, 2012).

No período de realização deste estudo (02/2015 a 05/2015), o aterro possuía 9 anos de operação, com uma área de aproximadamente $5.000 \mathrm{~m}^{2}$ e recebimento de aproximadamente 3.500 toneladas por ano de resíduos, originários dos municípios de Correia Pinto, Capão Alto, Bom Retiro, Bom Jardim da Serra, São Joaquim, São José do Cerrito, Painel, Ituporanga, Lages, Urupema e Urubici.

A geração média de lixiviado registrada no aterro foi de $108,48 \mathrm{~m}^{3} \cdot \mathrm{d}^{-1}, 14,2 \%$ maior que a vazão média considerada no projeto da estação de tratamento de efluentes (ETE), que era constituída por uma lagoa anaeróbia, seguida de duas lagoas facultativas, duas lagoas aeradas, tratamento físico-químico (baseado em coagulação e floculação com a utilização de PAC), duas lagoas de decantação, desinfecção (com o uso de pastilhas de cloro antes da zona de mistura da calha Parshall) e, por fim, descarte no corpo receptor (Figura 1). As siglas $P 1, P 2, P 3, P 4, P 5, P 6, P 7, P 8, P 9$ e $P 10$ se referem aos pontos ondem foram coletadas as amostras para caracterizar os efluentes de entrada e saída de cada etapa do tratamento. A Tabela 1 apresenta as características e parâmetros operacionais dos principais sistemas utilizados no tratamento do lixiviado gerado no aterro.

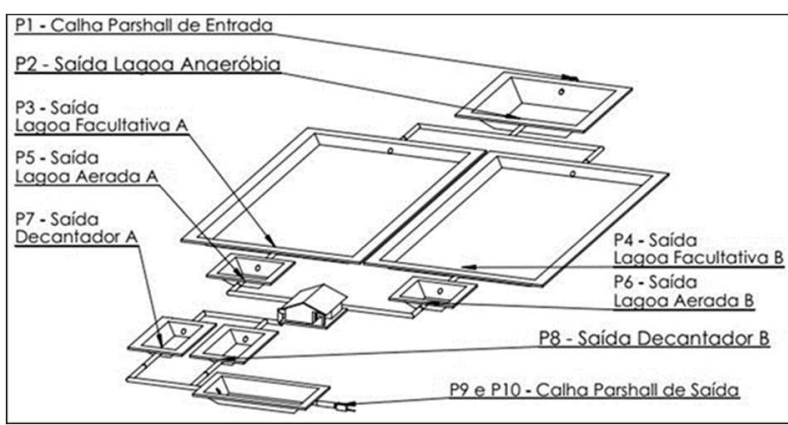

Figura 1: Layout da estação de tratamento de efluentes do aterro sanitário do município de Lages/SC.

Tabela 1: Características dos principais sistemas da estação de tratamento de efluentes do aterro sanitário de Lages/SC.

\begin{tabular}{|l|l|l|l|l|}
\hline Parâmetro & Lagoa anaeróbia & Lagoa facultativa & Lagoa aerada & Lagoa de decantação \\
\hline Quantidade & 1 & 2 & 2 & 2 \\
\hline Taxa de aplicação $\left(\mathrm{kgDBO}_{5} \cdot \mathrm{m}^{-3} \cdot \mathrm{d}^{-1}\right)$ & 0,20 & 380 & - & - \\
\hline Vazão média $\left(\mathrm{m}^{3} \cdot \mathrm{d}^{-1}\right)$ & 95 & 47,5 & 47,5 & 95 \\
\hline Concentração inicial $\left(\mathrm{kgDBO}_{5} \cdot \mathrm{m}^{-3}\right)$ & 4 & 2,4 & - & - \\
\hline Volume $\left(\mathrm{m}^{3}\right)$ & 1.900 & 4.360 & 207,7 & 263,3 \\
\hline TDH (dias) & 20 & 92 & 4 & 2 \\
\hline Eficiência esperada (\%) & 40 & 93,25 & 80 & 99,19 \\
\hline
\end{tabular}

\section{Monitoramento, Amostragem e Caracterização do Lixiviado}

O monitoramento da estação de tratamento de efluentes ocorreu por meio de análises dos parâmetros físicos, químicos e microbiológicas, realizados com frequência semanal. Ao total foram realizadas dez coletas, no período de 02/2015 a 05/2015. As coletas foram realizadas seguindo o Guia Nacional de Coletas e Preservação das Amostras (ANA, 2011). Para as amostras destinadas à analises microbiológicas, 
foram utilizados recipientes de vidro previamente auto clavados, sendo que no frasco de coleta para o P9, onde é realizada a etapa de desinfecção, foi adicionado tiossulfato de sódio (com o objetivo de remover possíveis interferências do cloro). As amostras destinadas para análises físicas e químicas foram coletadas em recipientes de polietileno, etiquetados conforme plano de amostragem pré-definido.

Após a coleta, as amostras foram acondicionadas em caixas térmicas de isopor, com o intuito de evitar alterações em suas características químicas e físicas por interferência da temperatura, e conduzidas para análise laboratorial. Nos dias em que foram realizadas as coletas também se efetuou o registro das vazões de entrada e saída de efluente nas calhas Parshall da estação de tratamento, além da leitura dos níveis de precipitação registrados em pluviômetros próximos a estação, de modo a verificar sua interferência no funcionamento da ETE.

\section{Caracterização do lixiviado bruto e do efluente tratado}

A caracterização do lixiviado bruto e do efluente tratado foi realizada por meio de análises físicas, químicas e microbiológicas conforme os procedimentos descritos pelo "Standard Methods for the Examination of Water and Wastewater" $21^{\text {st }}$ edition (APHA, 2005). Os parâmetros utilizados e os respectivos métodos são apresentados nas Tabelas 2 e 3. A Tabela 2 apresenta os parâmetros analisados que são exigidos por legislações ambientais, como a Resolução CONAMA n 430 de 13 de maio de 2011 e a Lei do Estado de Santa Catarina no 14.675 de 13 de abril de 2009.

Tabela 2: Parâmetros analisados, de acordo com as legislações vigentes em Santa Catarina, e respectivos métodos utilizados.

\begin{tabular}{|c|c|c|c|}
\hline $\begin{array}{c}\text { Parâmetros } \\
\text { físico-químicos }\end{array}$ & $\begin{array}{c}\text { Resolução CONAMA } \\
\text { no 430/2011 }\end{array}$ & Lei Estadual n¹4.675/2009 & Método \\
\hline $\mathrm{DBO}_{5}\left(\mathrm{mg} \cdot \mathrm{L}^{-1} \mathrm{O}_{2}\right)$ & $\begin{array}{l}120 \mathrm{mg.L}^{-1} \text { ou ST com eficiência } \\
\text { superior a } 60 \%\end{array}$ & $\begin{array}{l}60 \mathrm{mg}^{\mathrm{L}^{-1}} \text { ou ST com eficiência } \\
\text { superior a } 80 \%\end{array}$ & $5210 \mathrm{~B}$ \\
\hline Ferro total $\left(\mathrm{mg}^{\left.-\mathrm{L}^{-1}\right)}\right.$ & $15,0 \mathrm{mg} \cdot \mathrm{L}^{-1}$ & - & $3111 \mathrm{~B}$ \\
\hline Fósforo total $\left(\mathrm{mg}^{\mathrm{L}} \mathrm{L}^{-1}\right)$ & - & $\begin{array}{l}4,0 \mathrm{mg}^{\mathrm{L}^{-1}} \text { ou ST com eficiência } \\
\text { superior a } 75 \%\end{array}$ & $4500-P$ D \\
\hline Nitrogênio Amoniacal (mg. $\mathrm{L}^{-1}$ ) & $20 \mathrm{mg} \cdot \mathrm{L}^{-1}$ & - & $4500-\mathrm{NH}_{3} \mathrm{~B}$ \\
\hline $\mathrm{pH}$ & $5,0-9,0$ & $6,0-9,0$ & $4500-\mathrm{H}^{+} \mathrm{B}$ \\
\hline $\begin{array}{lll}\text { Sólidos } & \text { Sedimentáveis } & \text { Totais } \\
\left(\mathrm{mg} . \mathrm{L}^{-1}\right) & & \end{array}$ & $1,0 \mathrm{~mL} . \mathrm{L}^{-1}$ & $1,0 \mathrm{~mL} \cdot \mathrm{L}^{-1}$ & $2540 \mathrm{~F}$ \\
\hline Sulfeto $\left(\mathrm{mg} \cdot \mathrm{L}^{-1}\right)$ & $1,0 \mathrm{mg} \cdot \mathrm{L}^{-1}$ & - & $4500-S^{2-} F$ \\
\hline
\end{tabular}

Na Tabela 3 estão os parâmetros analisados para controle interno do aterro, sem exigência por parte de órgãos ambientais.

Tabela 3: Parâmetros analisados para controle operacional e métodos utilizados.

\begin{tabular}{|c|c|}
\hline Parâmetros físico-químicos & Método \\
\hline Cloreto $\left(\mathrm{mg} . \mathrm{L}^{-1}\right)$ & $4500-\mathrm{Cl}-\mathrm{B}$ \\
\hline Cloro $\left(m g . L^{-1}\right)$ & $4500 \mathrm{G}$ \\
\hline Coliformes Fecais (UFC.100mL-1 ) & $9222 \mathrm{D}$ \\
\hline Cor (uC) & $2120 \mathrm{~B}$ \\
\hline $\mathrm{DQO}\left(\mathrm{mg} \cdot \mathrm{L}^{-1} \mathrm{O}_{2}\right)$ & $5220 \mathrm{~B}$ \\
\hline $\mathrm{OD}\left(\mathrm{mg} \cdot \mathrm{L}^{-1}\right)$ & $4500-0 \mathrm{C}$ \\
\hline Sólidos Dissolvidos Totais $\left(\mathrm{mg} \cdot \mathrm{L}^{-1}\right)$ & $2540 \mathrm{C}$ \\
\hline Sólidos Fixos Totais (mg. $\mathrm{L}^{-1}$ ) & $2540 \mathrm{E}$ \\
\hline Sólidos Suspensos Totais (mg.t-1) & $2540 \mathrm{D}$ \\
\hline Sólidos Totais (mg..-1) & $2540 \mathrm{~B}$ \\
\hline Sólidos Voláteis Totais (mg. $\mathrm{L}^{-1}$ ) & $2540 \mathrm{E}$ \\
\hline Turbidez (FAU) & $2130 \mathrm{~B}$ \\
\hline
\end{tabular}




\section{Análise de Influência das condições climáticas na eficiência das lagoas}

Para o cálculo da correlação entre a eficiência de remoção de DBO e DQO do lixiviado (nas lagoas anaeróbia e facultativas) e os elementos climáticos, inicialmente foram obtidos dados diários de temperatura média, precipitação e insolação a partir do banco de dados do Instituo Nacional de Meteorologia (INMET). Para tanto, foram estimados os valores médios dos elementos climáticos com relação ao tempo de detenção hidráulico de cada lagoa. O cálculo da correlação entre a eficiência de remoção e os elementos já mencionados foi realizado com o uso do software Excel.

\section{RESULTADOS E DISCUSSÃO}

\section{Condições de Funcionamento da ETE}

Na Figura 2 estão apresentadas as precipitações pluviométricas e as vazões de entrada e saída da ETE, medidas durante o período de estudo. Apenas na segunda coleta ocorreu grande influência da precipitação nas vazões de entrada da ETE. Nas coletas seguintes, as vazões não apresentaram grandes alterações, muito se deve à quantidade menor de precipitação pluviométrica observada e ao tempo de percolação do lixiviado.

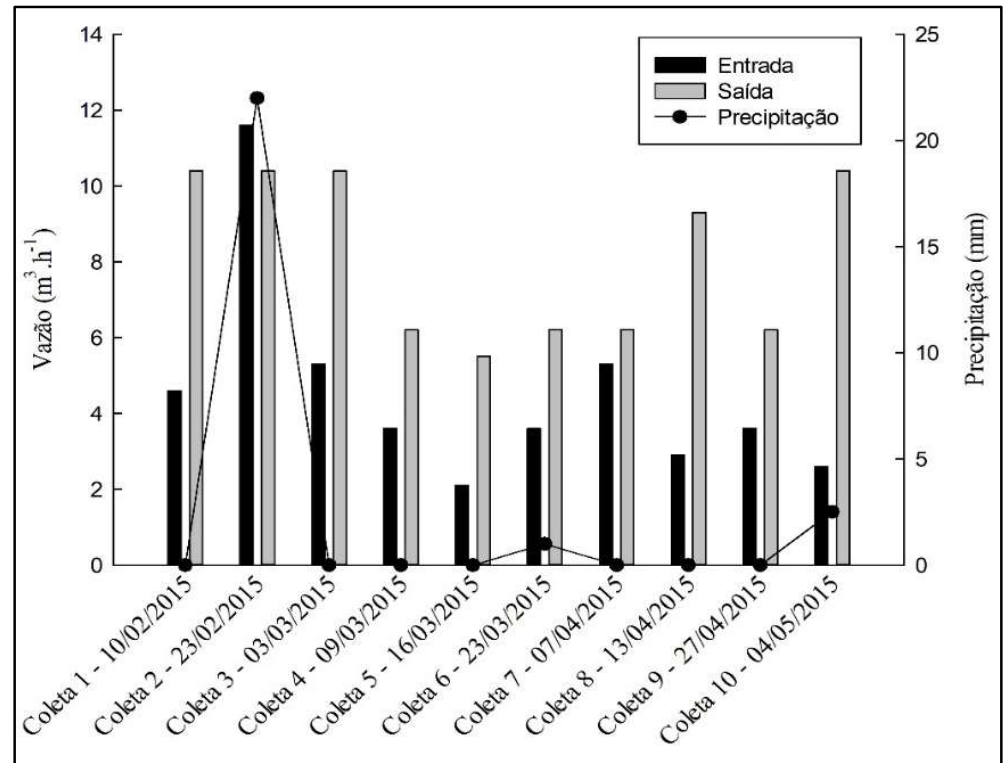

Figura 2: Precipitação pluviométrica e registro de vazões de entrada e saída da ETE.

Além disso, as vazões de saída foram superiores as vazões de entrada na maioria dos registros. Este fato se deve as lagoas estarem operando, em um período anterior ao monitoramento, próximas as suas capacidades máximas de volume e no período de realização do trabalho ocorreu a redução de seus níveis por controle de válvulas do tipo registro esférica, o que proporcionou um incremento nas vazões de saída.

Por meio dos dados obtidos também foi estimada a carga orgânica volumétrica (COV) que recebia a lagoa anaeróbia. Os valores apresentaram uma variação entre 0,02 e 0,16 $\mathrm{kgDBO}_{5} \cdot \mathrm{m}^{-3} \cdot \mathrm{d}^{-1}$ e estiveram abaixo do valor esperado para a lagoa $\left(0,20 \mathrm{kgDBO}_{5} \cdot \mathrm{m}^{-3} \cdot \mathrm{d}^{-1}\right)$. Entretanto, uma vez que o aterro está localizado em uma região conhecida por apresentar baixas temperaturas (EPAGRI, 2011), com temperatura mínima de 7,3 
@C e máxima de 30,8 ㄷ no período do estudo (INMET, 2018), menores taxas de aplicação volumétrica são admissíveis (VON SPERLING, 2017).

\section{Características do Lixiviado em Estudo e Eficiência do Sistema de Tratamento}

\section{pH}

Tanto para o lixiviado bruto quanto para o efluente tratado, nas diferentes etapas de tratamento, foi observada uma baixa variação dos valores de pH (Figura 3 - a). As amostras apresentaram tendência a um pH com características básicas (média de 7,8 00,2 para o lixiviado bruto). De acordo com o relatado por autores como Porowska (2015) e Wimmer et al. (2013), após as primeiras etapas de oxidação da matéria orgânica e com a continuação da degradação anaeróbia no aterro, a metanogênese se torna a fase predominante. Nesta fase ocorre redução nos teores de ácido acético e outros ácidos orgânicos gerados anteriormente, o que está associado ao aumento do $\mathrm{pH}$ do meio e pode justificar os resultados obtidos neste trabalho. Em outros estudos Dia et al. (2018), Xiao et al. (2013), Beck et al. (2010) e Méndez et al. (2002) também encontraram valores de $\mathrm{pH}$ com características básicas para o lixiviado bruto dos aterros estudados.

$\mathrm{O}$ pH nas lagoas de estabilização também pode variar ao longo da profundidade e ao longo do dia, fatores diretamente ligados à incidência de luminosidade e, consequentemente, à fotossíntese realizada pelas algas. Durante o dia, quando ocorre a máxima atividade fotossintética, o pH se eleva a valores próximos de 10 , o que pode gerar, entre outros fenômenos, a conversão de sulfeto $\left(\mathrm{H}_{2} \mathrm{~S}\right)$, causador de odores fétidos, em bissulfeto (HS'), que é inodoro (VON SPERLING, 2017). Caso o pH da lagoa se encontre próximo de 7, a maior parte dos sulfetos estará presente na forma HS', evitando a geração de odores, o que pode significar que o sistema de tratamento está equilibrado. Os problemas de maus odores provêm dos baixos valores de pH (VON SPERLING, 2017).

Para o adequado desenvolvimento das bactérias metanogênicas, o pH do meio deve ser próximo ou superior à neutralidade, entre outras condições ambientais específicas (adequada temperatura e ausência de oxigênio dissolvido). Nos casos em que estas condições não são atendidas, sua taxa de reprodução pode ser reduzida, causando acúmulo dos ácidos formados na etapa de liquefação e formação de ácidos pelas bactérias acidogênicas, gerando, como consequência, a perda de eficiência na remoção de DBO e a geração de maus odores, uma vez que haveria poucas bactérias metanogênicas para dar continuidade à conversão dos ácidos (VON SPERLING, 2017). Destaca-se ainda, que os valores obtidos para o efluente final se encontram dentro dos limites estabelecidos pela Resolução CONAMA 430/2011 e pela Lei do Estado de Santa Catarina no 14.675/2009.

\section{Demanda bioquímica de oxigênio $\left(\mathrm{DBO}_{5}\right.$ e demanda bioquímica de oxigênio (DQO)}

No período analisado, o maior ganho de eficiência do sistema se encontra no conjunto constituído por lagoa anaeróbia seguida por lagoa facultativa, também conhecido como sistema australiano (VON SPERLING, 2017). Ainda de acordo com Von Sperling (2017), esse conjunto pode obter eficiência de remoção 
entre 75 e 85\% para DBO e entre 65 e 80\% para DQO. No entanto, apesar da eficiência de remoção da DBO $(82,4 \%)$ estar de acordo com o descrito pelo autor supracitado, a baixa eficiência na remoção de DQO $(37,2 \%)$ no conjunto de lagoas pode indicar a presença de compostos recalcitrantes no lixiviado do aterro.

Destaca-se que, apesar de localizado em uma região de clima frio, a boa eficiência observada no conjunto, com relação à $\mathrm{DBO}$, pode estar relacionada com a temperatura amena registrada na região no período de coleta das amostras, média diária de 18,22 $\pm 2,49$ ㄷ , de acordo com dados do Instituto Nacional de Meteorologia (INMET, 2015). Entretanto, o sistema australiano sofre grande influência da temperatura do meio, sobretudo na taxa de crescimento da biomassa e na conversão do substrato, o que torna a aplicação do sistema menos favorável em locais com baixas temperaturas (VON SPERLING, 2017).

Dessa forma, apesar da pequena contribuição para a eficiência global do tratamento no período de estudo (12,5\% DBO e 2,4\% DQO), a utilização de um sistema complementar constituído por lagoa aerada e lagoa de decantação é justificável por possuir maior independência das condições climáticas do que o sistema australiano (VON SPERLING, 2017) e, consequentemente, suprir o déficit de eficiência que pode ocorrer nas lagoas iniciais nos meses de inverno.

Com relação ao efluente tratado, a concentração média de $\mathrm{DBO}_{5}$ foi de $64 \mathrm{mg} \cdot \mathrm{L}^{-1}$ e a eficiência média do sistema de tratamento foi de $96,18 \%$ (Figura 3b), o que se enquadra no exigido pelas legislações em vigor. Para o lixiviado bruto, do aterro sanitário de Lages/SC, as concentrações médias de $\mathrm{DBO}_{5}\left(1.677,8 \mathrm{mg} \cdot \mathrm{L}^{-1}\right)$ e DQO $\left(5.468,1\right.$ mg. $\left.\mathrm{L}^{-1}\right)$ também apresentaram semelhança com os valores obtidos no estudo dirigido por Beck et al. (2010). Os autores encontraram concentrações de $\mathrm{DBO}_{5}$ e $\mathrm{DQO}$ de $1.480,0 \mathrm{mg} \cdot \mathrm{L}^{-1}$ e $5.496,0 \mathrm{mg} \cdot \mathrm{L}^{-1}$, respectivamente, no lixiviado do aterro de Passo Fundo/RS.

Esta semelhança pode ser justificada, principalmente, pela proximidade da idade de operação dos aterros, sendo de 9 anos para Lages e 8 anos para o aterro de Passo Fundo. Renou et al. (2008), relatam que a idade dos aterros é um dos principais fatores que interferem nas características do lixiviado gerado. De acordo o tempo de operação do aterro pode ser observada grande variação da concentração de componentes, tais como compostos recalcitrantes e substâncias húmicas (MANDAL et al., 2017).

Destaca-se ainda que, conforme o descrito por Renou et al. (2008), os valores de DQO observados para o lixiviado do aterro sanitário de Lages o caracterizam como um lixiviado de aterro com idade 'intermediária', com média biodegradabilidade, pois estão situados entre $4.000 \mathrm{mg} \cdot \mathrm{L}^{-1} \mathrm{e} 10.000 \mathrm{mg} . \mathrm{L}^{-1}$. Esta classificação também condiz com a idade de operação do aterro, uma vez que lixiviados de aterros com idade entre 5 e 10 anos são classificados desta maneira (RENOU et al., 2008).

Outro fator que indica que o lixiviado do aterro de Lages está tendendo para uma menor biodegradabilidade é a relação $\mathrm{DBO}_{5} / \mathrm{DQO}$ observada. Para o lixiviado bruto, neste estudo, o valor médio da relação foi de 0,34 , o qual já está bastante próximo do valor de 0,29, encontrado por Dia et al. (2018) ao analisarem o lixiviado bruto gerado em um aterro com aproximadamente 15 anos de operação na província de Québec, no Canadá.

Esta classificação está relacionada, principalmente, ao tipo de tratamento adequado para o efluente, uma vez que a medida em que a idade de operação do aterro aumenta a recalcitrância do lixiviado também 
tende a aumentar (MANDAL et al., 2017). Desta forma, o tratamento biológico, utilizado na maioria dos casos, pode tornar-se insuficiente e etapas de tratamento complementares tornam-se necessárias (XIAO et al., 2013). Recentemente, novas técnicas vêm sendo aplicadas e avaliadas para o tratamento de lixiviados considerados de alta recalcitrância. Dia et al. (2018), por exemplo, estudaram o uso de eletrocoagulação seguida de biofiltração e obtiveram resultados satisfatórios.

Scandelai et al. (2018), ao utilizar processo de tratamento baseado na combinação de ozonização e oxidação supercrítica de água, obtiveram um lixiviado tratado em conformidade com a maioria dos parâmetros citados pela legislação brasileira. Além disso, também se pode citar a avaliação do uso de processos oxidativos avançados, osmose reversa e biorreatores no tratamento do lixiviado em diferentes aterros sanitários (CALABRÒ et al., 2018; COSTA et al., 2018; PENG et al., 2018).

Nesse sentido, visto que o aterro sanitário do município de Lages tende para uma idade avançada de operação, a adequação do sistema de tratamento deve ser planejada com antecedência de modo que se possa continuar operando com eficiência satisfatória frente a um efluente que futuramente pode apresentar um predomínio de compostos recalcitrantes.

\section{Ferro total}

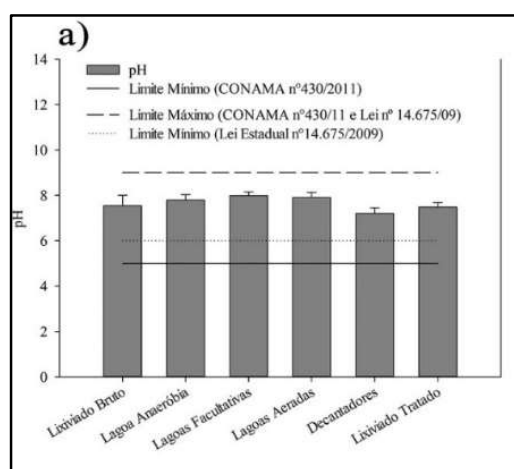

c)
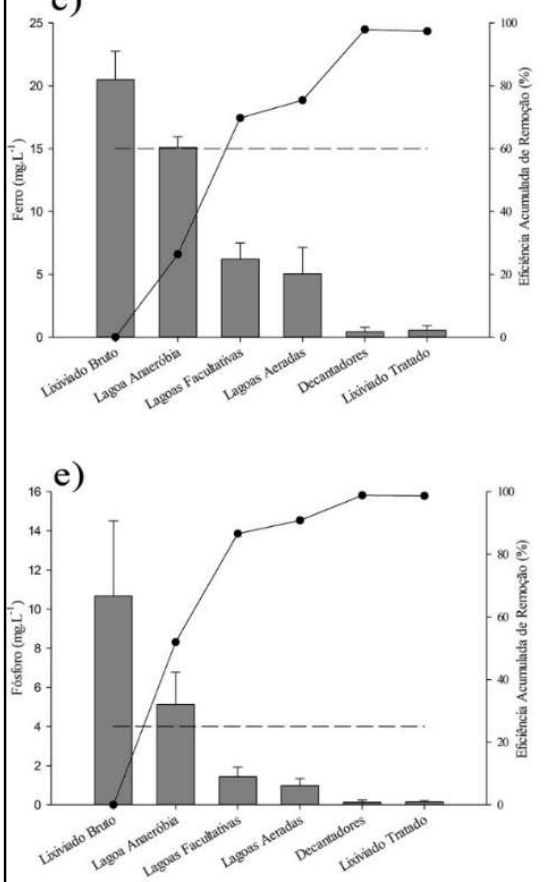

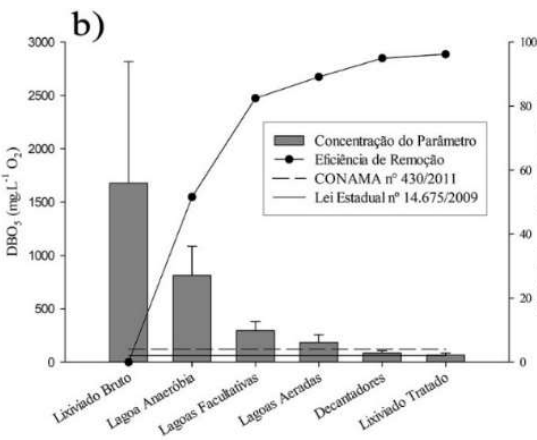

d)
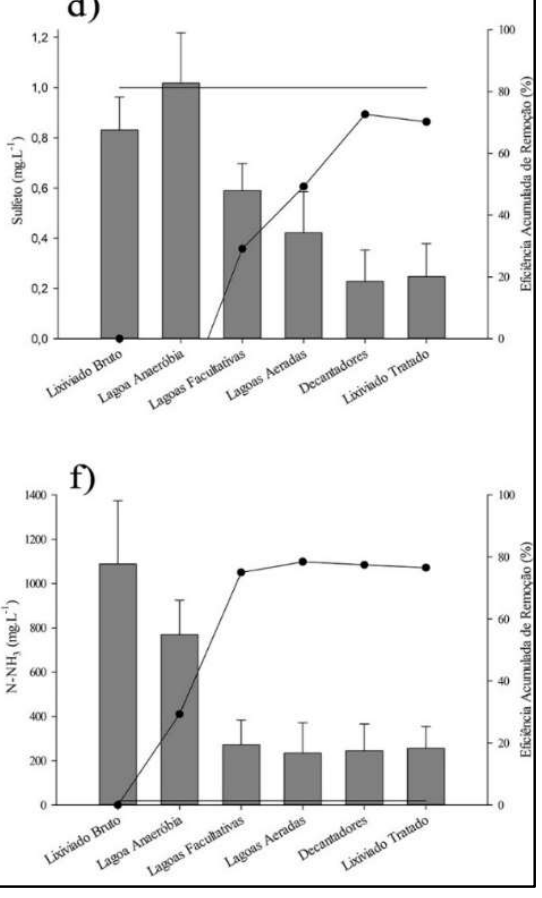

Figura 3: Variação da concentração ao longo das etapas de tratamento e eficiência do sistema de tratamento para: a) $\mathrm{pH}$; b) $\mathrm{DBO}_{5}$; c) Ferro total; d) Sulfeto; e) Fósforo total; f) Nitrogênio amoniacal. 
Para o lixiviado bruto a concentração média de ferro foi de $20,5 \mathrm{mg} \cdot \mathrm{L}^{-1}$, bastante próxima ao valor de 24,7 mg.L $\mathrm{L}^{-1}$ encontrado por Dia et al. (2018) e acima do valor de $7 \mathrm{mg} \cdot \mathrm{L}^{-1}$ descrito por Carley et al. (1991), o que reforça as diferenças que podem ocorrer no lixiviado em função da composição dos resíduos sólidos urbanos destinados para aterros sanitários em diferentes localidades. Além disso, neste estudo, foi constatado que processo de tratamento avaliado apresentou uma eficiência média de 97,33\% (Figura 3c) e o efluente final estava de acordo com os padrões de lançamento de efluentes no Estado de Santa Catarina.

\section{Sulfeto}

A concentração de sulfeto observada para o lixiviado bruto foi em média de $0,8 \mathrm{mg} \cdot \mathrm{L}^{-1}$. Além disso, foi observado um aumento na concentração de sulfetos do efluente tratado pela lagoa anaeróbia com relação ao lixiviado bruto (Figura 3d). Este acréscimo é esperado e é justificado pela redução do sulfato a sulfeto, que ocorre em condições anaeróbias (VON SPERLING, 2017). O autor também relata que em situações onde são observados baixos valores de pH pode existir a ocorrência de maus odores. Entretanto, este comportamento não foi observado neste trabalho. O sistema de tratamento, em sua totalidade, apresentou desempenho satisfatório com relação a este parâmetro. Sendo que o efluente tratado apresentou uma concentração média de $0,25 \mathrm{mg}^{-\mathrm{L}^{-1}}$, estando também em conformidade com os padrões exigidos pela legislação.

\section{Fósforo total}

Para fósforo total o lixiviado bruto apresentou concentrações médias em torno de 10,7 mg.L-1. Já Dia et al. (2018) encontraram valores de 4,89 mg. $\mathrm{L}^{-1}$ e Méndez et al. (2002) de 45,5 mg.L-1. Estas diferenças também estão, possivelmente, relacionadas as características do resíduo e aos modos de operação do aterro. Ademais, a estação de tratamento mostrou-se eficiente na redução deste parâmetro, com redução média de 98,62 \% de fósforo. A elevada remoção, observada na lagoa anaeróbia (Figura 3e), pode ter relação com a precipitação de fosfatos que ocorre em elevadas condições de $\mathrm{pH}$, os quais podem ter precipitado na forma de estruvita ou hidroxiapatita (VON SPERLING, 2017).

\section{Nitrogênio amoniacal}

Apesar da eficiência de remoção de 76,52\% (Figura 3 - f), a concentração no efluente tratado foi de 255,51 mg. $\mathrm{L}^{-1}$. Deste modo, este parâmetro encontra-se em desconformidade com o estabelecido pela resolução CONAMA 430/2011, a qual determina uma concentração máxima para lançamento de efluentes em corpos hídricos de $20 \mathrm{mg} \cdot \mathrm{L}^{-1}$.

A alta concentração remanescente no efluente tratado pode estar relacionada ao fato de que efluentes que apresentam nitrogênio amoniacal em concentrações de 500 a 1.000 mg. $\mathrm{L}^{-1}$, juntamente com valores de DQO acima de $2.000 \mathrm{mg} \cdot \mathrm{L}^{-1} \mathrm{e}$ alta alcalinidade, são considerados como de difícil tratamento por processo biológico, principalmente devido à alta toxicidade do nitrogênio (CLÉMENT et al., 1995). Além disso, um dos fatores que dificulta a remoção de amônia na atual configuração da ETE, é a falta de ajuste de pH. 
Sendo que, como a ETE atualmente faz uso de aeração mecânica, a amônia poderia ser removida pela técnica de stripping, ou seja, arraste com ar (YAO et al., 2017).

Uma alternativa para isso pode ser o processo de oxidação anaeróbia de amônia, ou simplesmente ANAMMOX (anaerobic ammonium oxidation). Conforme Zhang et al. (2008), este processo remove dois poluentes simultaneamente, de modo que converte amônia e nitrito, sob condições anóxicas, em nitrogênio gasoso. De acordo Scheeren et al. (2011), o processo ANAMMOX apresenta economia no tamanho de reatores, além de uma redução de aproximadamente $60 \%$ no consumo de energia quando comparado ao processo convencional (por não necessitar de aeração).

Em caso de área disponível, uma outra alternativa seria o uso de lagoas de maturação. De acordo com Von Sperling (2017), as características destas lagoas favorecem a volatilização do $\mathrm{NH}_{3}$ e uma parcela deste composto também pode ser consumida diretamente por algas. Além disso, em casos de lagoas de maturação especialmente rasas, podem ser atingidas elevadas taxas de remoção de amônia. Isto pode

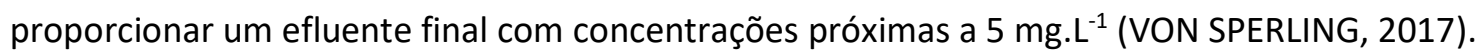

\section{Oxigênio dissolvido (OD)}

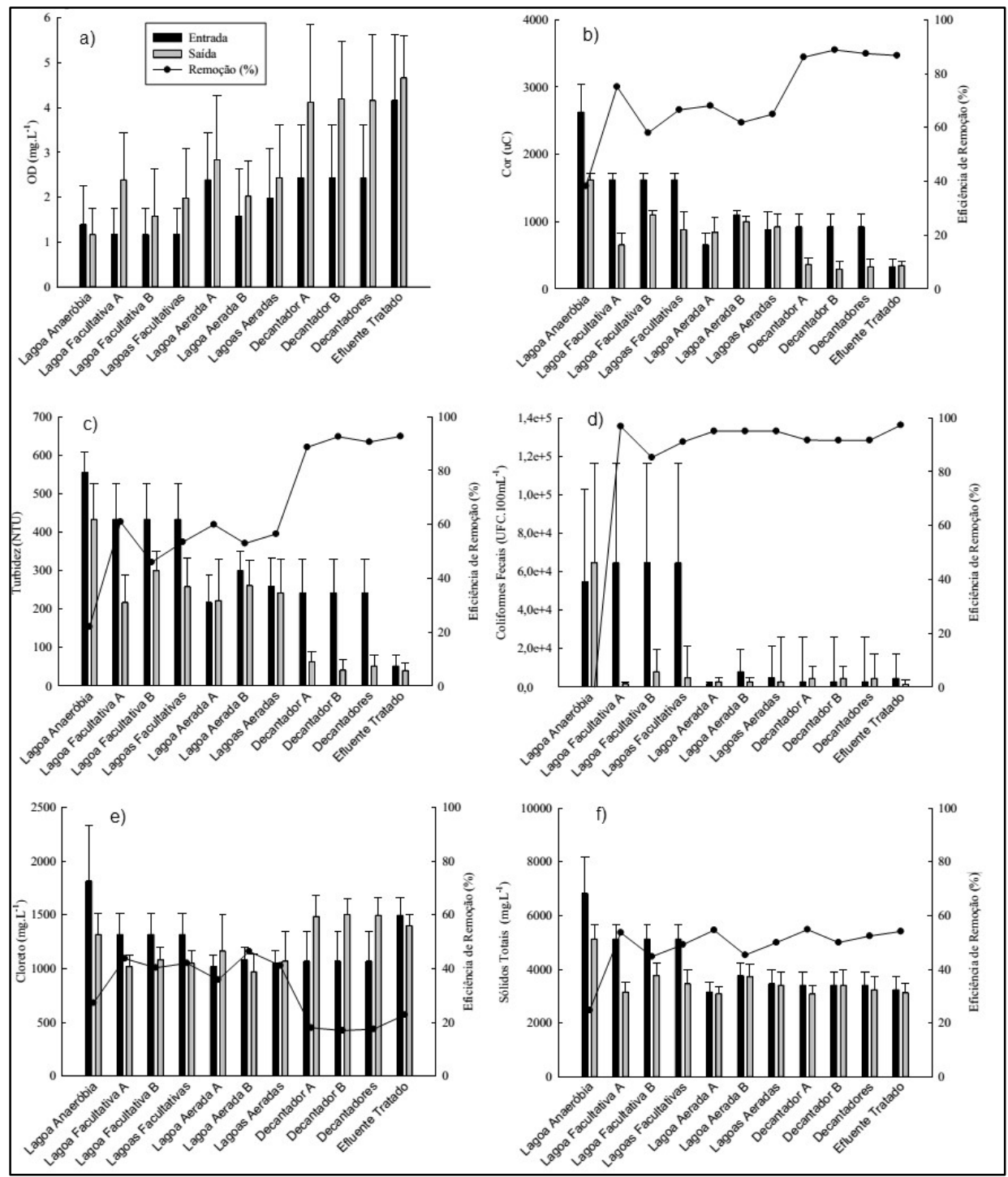

Figura 4: Variação da concentração ao longo das etapas de tratamento e eficiência de remoção de: a) OD; b) Cor; c) Turbidez; d) Coliformes fecais; e) Cloreto; f) Sólidos totais. 
Os níveis de oxigênio foram utilizados para avaliar as condições de operação das lagoas. Conforme esperado, nas lagoas facultativas e aeradas ocorreu aumento gradativo das concentrações de OD (Figura 4a). Entretanto, em algumas coletas foram registrados valores atípicos na lagoa anaeróbia. Este fato pode estar relacionado a amostragem ter sido realizada muito próxima a superfície, o que interferiu no monitoramento das reais condições de operação da lagoa.

\section{Cor e turbidez}

Após a etapa de coagulação e floculação, com o uso de PAC, a cor reduziu de 921 para 329 uC (64,28\% de redução). O valor médio de cor no lixiviado bruto foi de 2.626,7 uC, o qual foi reduzido ao longo das etapas de tratamento (Figura 4b). Lin et al. (2000) realizaram experimentos de coagulação química, também com o uso do coagulante PAC, e por meio de ensaios com equipamento Jar Test obtiveram, similarmente, reduções de mais de $50 \%$ na cor do lixiviado em estudo.

Também foi observado que a turbidez média encontrada no lixiviado bruto, do aterro sanitário do município de Lages, foi de 555,6 NTU, um valor intermediário entre os valores de 130,0 e 1.120,0 NTU encontrados por Méndez et al. (2002) e Beck et al. (2010), respectivamente. Destaca-se, ainda, que a eficiência média de remoção da turbidez foi de $92,80 \%$, sendo que o melhor resultado também foi observado após a utilização do coagulante PAC. Após esta etapa, ocorreu redução de $78 \%$ da turbidez com relação ao efluente proveniente das lagoas aeradas (Figura 4c).

\section{Coliformes fecais}

Os valores de coliformes fecais foram de $6,47.10^{4}$ UFC. $100 \mathrm{~mL}^{-1}$, para o lixiviado bruto, neste monitoramento. Este resultado está na mesma magnitude dos descritos por Beck et al. (2010), onde foram encontrados valores de $2,00.10^{4} \mathrm{UFC} \cdot 100 \mathrm{~mL}^{-1}$. A redução mais significativa, para este parâmetro foi observada nas lagoas de estabilização secundárias (Figura 4-e). Está elevada eficiência está de acordo com o descrito por Von Sperling (2005), que ao analisar dados de 186 lagoas (entre facultativas e de maturação) relatou que as lagoas secundárias obtiveram em média $90 \%$ de remoção de coliformes e que este desempenho se deve, possivelmente, ao alto tempo de detenção hidráulico observado neste tipo de lagoa.

\section{Cloro residual livre}

Foi verificada que a concentração média de cloro residual livre no efluente após a etapa de desinfecção foi de $0,70 \mathrm{mg} \cdot \mathrm{L}^{-1}$. O uso do cloro na desinfecção de efluentes, apesar de eficiente na eliminação de microrganismos e patógenos, pode dar origem a subprodutos perigosos (METCALF et al., 2016). De acordo com Wang et al. (2007), a formação de alguns destes subprodutos, como os trialometanos e os ácidos haloacéticos, já tem sido estudada. No entanto, ainda é difícil detectar todos os possíveis subprodutos formados na desinfecção de efluentes.

Watson et al. (2012), por meio de bioensaios, avaliaram o impacto toxicológico destes subprodutos, formados pelo uso de cloro em águas residuárias, e concluíram que estes compostos podem ser tóxicos e ter 
um impacto deletério em organismos aquáticos expostos a eles. De modo a minimizar esses riscos e também se obter uma eliminação de patógenos eficiente, as lagoas de maturação continuam sendo uma opção, pois constituem uma alternativa bastante econômica com relação a cloração (VON SPERLING, 2017).

\section{Cloreto}

Neste trabalho, a concentração média de cloreto no lixiviado bruto foi de $1.812 \mathrm{mg} \cdot \mathrm{L}^{-1}$. Concentrações semelhantes $\left(1.820,0 \mathrm{mg} \cdot \mathrm{L}^{-1}\right)$ foram observadas em um estudo realizado. Entretanto, este também é um parâmetro que tende a apresentar variações de acordo com as características dos resíduos e de operação do aterro. Xiao et al. (2013), por exemplo, encontraram concentrações de cloreto entre 4.200 e 5.000 mg.L-1 , Méndez et al. (2002) descreveram concentrações médias de 3.332 mg.L-1 e, em contrapartida, a concentração média descrita no trabalho de Beck et al. (2010) foi de apenas $780 \mathrm{mg} \cdot \mathrm{L}^{-1}$.

Destaca-se ainda, que após a passagem do efluente da lagoa aerada para os decantadores é possível observar um aumento na concentração de cloreto (Figura 4e). Isto está relacionado, sobretudo, pela adição do coagulante PAC. Este coagulante caracteriza-se como um composto químico constituído, principalmente, de alumínio e cloro, sendo que este último representa aproximadamente $16 \%$ de sua composição (CHEN et al., 2016).

\section{Série de sólidos}

De acordo com as análises realizadas foi possível observar uma remoção de sólidos dissolvidos totais (SDT) de aproximadamente $55,45 \%$, para sólidos fixos totais (SFT), a eficiência do sistema de tratamento foi próxima a 40,70\%. Já para sólidos voláteis totais (SVT), observou-se uma redução média de 73,19\%. Com relação aos sólidos suspensos totais (SST), a redução foi de $71,33 \%$ e para sólidos totais (ST) a remoção foi de aproximadamente $54,11 \%$ até o final do tratamento (Figura $4 \mathrm{f}$ ).

Ressalta-se que da concentração média de $6.821,3 \mathrm{mg} \cdot \mathrm{L}^{-1}$ de ST no lixiviado bruto, apenas $98,2 \mathrm{mg} \cdot \mathrm{L}^{-}$

${ }^{1}$ se caracterizavam como SST, o que implica que a maior parte da concentrações de sólidos se encontrava dissolvida no lixiviado. Resultados semelhantes pata SST foram apresentados por Méndez et al. (2002), onde foram descritas concentração de apenas $88,0 \mathrm{mg} \cdot \mathrm{L}^{-1}$. Por outro lado foi citado que lixiviados teve concentrações médias de SST próximas a $920,0 \mathrm{mg} \cdot \mathrm{L}^{-1}$. Quanto a análise de sólidos sedimentáveis totais, esta foi realizada apenas para amostras do efluente tratado. No entanto, as amostras não apresentaram sólidos sedimentáveis em nenhuma das coletas e, desta forma, também atingiram os padrões estabelecidos pelas legislações vigentes no Estado de Santa Catarina.

\section{Influência dos elementos climáticos}

A correlação existente entre a eficiência de remoção de DBO e DQO com os elementos climáticos analisados para ambas as lagoas que integram o sistema de lagoas de estabilização podem ser observados na Tabela 4. Valores próximos de 1,00 indicam que existe correlação entre os fatores, ou seja, o comportamento de um fator influencia no comportamento do outro fator. 
Tabela 4: Correlação entre eficiência de remoção de DBO e DQO e elementos climáticos.

\begin{tabular}{|l|l|l|l|}
\hline & Elementos climáticos & Lagoa anaeróbia & Lagoa facultativa \\
\hline \multirow{4}{*}{ Remoção DBO } & Temperatura média & $-0,952$ & $-0,805$ \\
\cline { 2 - 4 } & Precipitação & 0,015 & $-0,729$ \\
\cline { 2 - 4 } & Insolação & $-0,836$ & 0,075 \\
\hline \multirow{2}{*}{ Remoção DQO } & Temperatura média & 0,283 & $\mathbf{0 , 5 8 9}$ \\
\cline { 2 - 4 } & Precipitação & $-0,080$ & $\mathbf{0 , 5 5 9}$ \\
\cline { 2 - 4 } & Insolação & 0,183 & 0,023 \\
\hline
\end{tabular}

Pode-se perceber que não há correlação entre a eficiência de remoção de DBO das lagoas anaeróbia e facultativas com os elementos climáticos de temperatura, precipitação e insolação média. No caso da DQO, observou-se que a temperatura média e a precipitação apresentaram maior correlação com a eficiência do tratamento do lixiviado na lagoa facultativa. Entretanto, considerando que os dados de temperatura e precipitação no período de coleta foi bastante homogêneo (Figura 5), a eficiência no tratamento parece advir principalmente de fatores relacionados às características do lixiviado bruto. Já no estudo realizado por D’Alessandro et al. (2015) em Trindade (Goiás), a redução das concentrações de DBO e DQO nas lagoas anaeróbia e facultativa foi relacionado com o aumento da precipitação durante os períodos chuvosos, devido ao aumento na diluição dos nutrientes. A temperatura, neste caso, influenciou apenas a concentração de OD do efluente bruto, sendo inversamente proporcional.

Scaratti et al. (2014) realizou um estudo sobre a influência das condições hidroclimáticas no tratamento de esgoto sanitário nos municípios de Arroio Trinta e Herval d'Oeste, ambos localizados na região meio oeste de Santa Catarina, onde obtiveram baixas taxas de remoção de DBO $(55,1 \%)$ e DQO $(23,8 \%)$, as quais foram associadas aos meses de menor insolação, menor temperatura (prejudica o metabolismo dos microrganismos) e maior precipitação pluviométrica em ambos os sistemas (lagoa anaeróbia e facultativa).

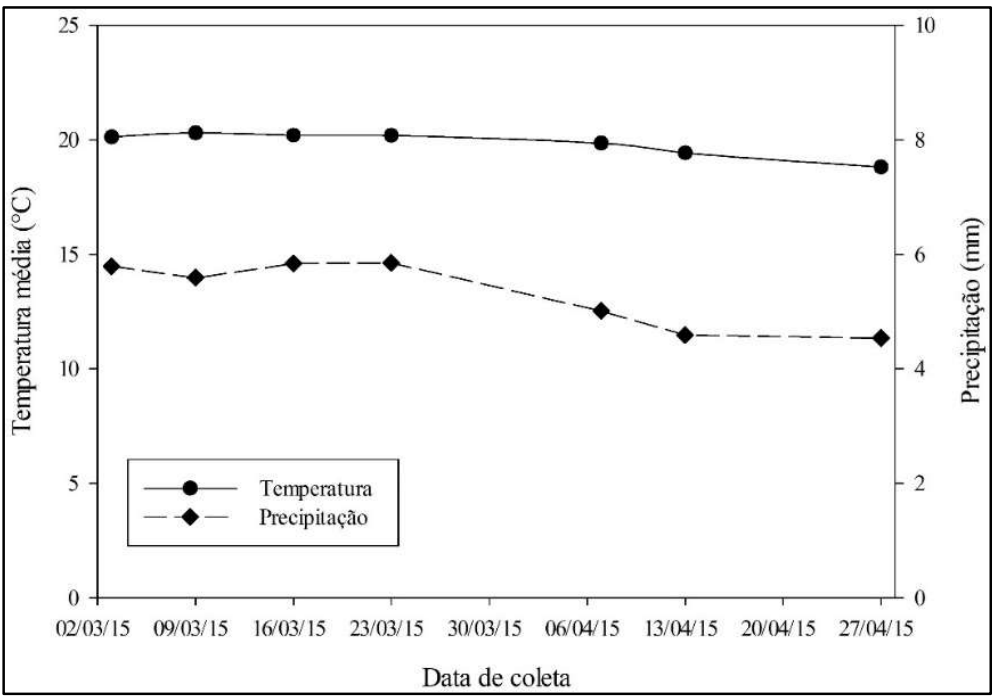

Figura 5: Dados de temperatura média e precipitação do período de coleta de amostras (considerando o TDH do lixiviado na lagoa facultativa).

\section{CONCLUSÕES}

Neste trabalho foram realizadas análises física, químicas e microbiológicas para avaliar o desempenho operacional da estação de tratamento de chorumes de um aterro sanitário localizado na serra catarinense. Para os parâmetros citados pela Resolução do Conselho Nacional do Meio Ambiente no 
430/2011 e pela Lei do Estado de Santa Catarina no 14.675/2009, os resultados obtidos foram comparados com os limites estabelecidos. Com exceção do nitrogênio amoniacal, todos os parâmetros apresentaram-se em conformidade com o exigido pelas legislações supracitadas. Apesar de a temperatura média do local ser inferior à de outras estações relatadas na literatura, o desempenho do sistema foi comparável àqueles observados em locais de climas com temperaturas maiores. A execução deste trabalho pode auxiliar na identificação de oportunidades de melhorias e alternativas para a operação da estação de tratamento de efluentes de aterros sanitários em outros municípios.

\section{REFERÊNCIAS}

AHARONI, I.; SIEBNER, H.; DAHAN, O.. Application of vadosezone monitoring system for real-time characterization of leachate percolation in and under a municipal landfill. Waste Management, v.67, p.203-213, 2017. DOI: http://doi.org/10.1016/j.wasman.2017.05.012

AKINBILE, C. O.. Environmental impact of landfill on groundwater quality and agricultural soils in Nigeria. Soil and Water Research, v.7, n.1, p.18-26, 2012.

ANA. Agência Nacional de Águas. Guia Nacional de Coleta e Preservação de Amostras: Água, Sedimento, Comunidades Aquáticas e Efluentes Líquidos. São Paulo: ANA, 2011.

APHA. American Public Health Association. Standard Methods for Examination of Water and Wastewater. 21 ed. Washington: APHA, 2005.

BECK, M. H.; KORL, E. P.; SANTOS, V. R.; THOMÉ, A. ESCOSTEGUY, P. A. V.. Monitoramento das Águas Subterrâneas e Lixiviado do Local de Disposição dos Resíduos Sólidos Urbanos do Município de Passo Fundo/RS. Rega, v.7, n.1, p.29-44, 2010.

BESEN, G. R.; FRACALANZA, A. P.. Challenges for the Sustainable Management of Municipal Solid Waste in Brazil. Disp, v.52, n.2, p.45-52, 2016. DOI:

http://doi.org/10.1080/02513625.2016.1195583

BHALLA, G.; SWAMEE, P. K.; UMAR, A.; BANSAL, A.. Assessment of groundwater quality near municipal solid waste landfill by an Aggregate Index Method. Agris On-line Papers in Economics and Informatics, v.2, n.3, p.1492-1503, 2012. DOI: http://doi.org/10.6088/ijes.002020300034

CALABRÒ, P. S.; GENTILI, E.; MEONI, C.; ORSI, S.; KOMILIS, D. Effect of the recirculation of a reverse osmosis concentrate on leachate generation: A case study in an Italian landfill. Waste Management, v.76, p.643-651, 2018. DOI: http://doi.org/10.1016/j.wasman.2018.03.007

CARLEY, B. N.; MALVINIC, D. S.. The effects of external carbon loading on nitrification and denitrification of a highammonia landfill leachate. Research Journal WPCF, v.63, n.1, p.51-59, 1991

CHEN, W.; LI, B.; LI, Q.; TIAN, J.. Effect of polyaluminum chloride on the properties and hydration of slag-cement paste. Construction and Building Materials, v.124, p.10191027, 2016. DOI:

http://doi.ogr.10.1016/i.conbuildmat.2016.08.154
CLÉMENT, B.; MERLIN, G.. The contribution of ammonia and alkalinity to landfill leachate toxicity to duckweed. Science of the Total Environment, v.170, n.1-2, p.71-79, 1995. DOI: http://doi.org/10.1016/0048-9697(95)04563-G

COSTA, F. M.; DAFLON, S. D. A.; BILA, D. M.; FONSECA, F. V.; CAMPOS, J. C.. Evaluation of the biodegradability and toxicity of landfill leachates after pretreatment using advanced oxidative processes. Waste Management, v.76, p.606-613, 2018. DOI: http://doi.org.10.1016/j.wasman.2018.02.030

D'ALESSANDRO, E. B.; SAAVEDRA, N. K.; SANTIAGO, M. F.; D'ALESSANDRO, N. C. O.. Influência da sazonalidade em lagoas de estabilização. Ingeniería del Agua, v.19, n.4, 2015. DOI: http://doi.org/10.4995/ia.2015.3418

DIA, O.; BUELNA, G.; DROGUI, P.; DUBÉ, R.. Hybrid process, electrocoagulation-biofiltration for landfill leachate treatment. Waste Management, v.75, p.391-399, 2018. DOI: http://doi.org/10.1016/j.wasman.2018.02.016

EMBRAPA. Empresa Brasileira de Pesquisa Agropecuária. Atlas climático da Região Sul do Brasil: Estados do Paraná, Santa Catarina e Rio Grande do Sul. 2 ed. Brasília: Livraria Embrapa, 2012.

EPAGRI. Empresa de Pesquisa Agropecuária e Extensão Rural de Santa Catarina. Média das temperaturas mínimas $\left({ }^{\circ} \mathrm{C}\right)$ mensais em SC nos meses de inverno. Florianópolis: CIRAM, 2011.

HAN, Z.; SHI, G.; MA, H.; HE, L.. A review of groundwater contamination near municipal solid waste landfill sites in China. Science of the Total Environment, v.569-570, n.1, p.1255-1264, 2016. DOI:

http://doi.org/10.1016/j.scitotenv.2016.06.201

INMET. Instituto Nacional de Meteorologia. Banco de Dados Meteorológicos para Ensino e Pesquisa. Brasília: INMET, 2015.

INMET. Instituto Nacional de Meteorologia. Banco de Dados Meteorológicos para Ensino e Pesquisa. Brasília: INMET, 2018.

LI, Y.; LI, J.; DENG, C.. Occurrence, characteristics and leakage of polybrominated diphenyl ethers in leachate from municipal solid waste landfills in China. Environmental Pollution, v.184, p.94-100, 2014. DOI: 
http://doi.org/10.1016/j.envpol.2013.08.027

LIN, S. H.; CHANG, C. C.. Treatment of landfill leachate by combined electro-fenton oxidation and sequencing batch reactor method. Water Research, v.34, n.17, p.4243-4249, 2000.

MANDAL, P.; DUBEY, B. K.; GUPTA, A. K.. Review on landfill leachate treatment by electrochemical oxidation: Drawbacks, challenges and future scope. Waste Management, v.69, p.250-273, 2017. DOI: http://doi.org/10.1016/j.wasman.2017.08.034

MÉNDEZ, N. R. I.; SANDOVAL, E. C.; RIANCHO, M. R. S.; BPRGES, E. R. C.. Influencia del material de cubierta en la composición de los lixiviados de un relleno sanitario. Ingeniería, v.2, p.7-12, 2002.

METCALF, L.; EDDY, H. P.. Tratamento de Efluentes e Recuperação de Recursos. 5 ed. Rio de Janeiro: McGraw Hill, 2016.

MORAVIA, W. G.; AMARAL, M. C. S.; LANGE, L. C.. Evaluation of landfill leachate treatment by advanced oxidative process by Fenton's reagent combined with membrane separation system. Waste Management, v.33, n.1, p.89-101, 2013. DOI: http://doi.org/10.1016/j.wasman.2012.08.009

PENG, W.; PIVATO, A.; LAVAGNOLO, M. C.. Digestate application in landfill bioreactors to remove nitrogen of old landfill leachate. Waste Management, v.74, p.335-346, 2018. DOI: http://doi.org/10.1016/j.wasman.2018.01.010

POROWSKA, D.. Determination of the origin of dissolved inorganic carbon in groundwater around a reclaimed landfill in Otwock using stable carbon isotopes. Waste Management, v.39, p.216-225, 2015. DOI: http://doi.org/10.1016/i.wasman.2015.01.044

REGADÍO, M.; RUIZ, A. I.; SOTO, I. S.; RASTRERO, M. R.; SÁNCHEZ, N.; GISMERA, M. J.; SEVILLA, M. T.; SILVA, P.; PROCOPIO, J. R.; CUEVAS, J.. Pollution profiles and physicochemical parameters in old uncontrolled landfills. Waste Management, v.32, n.3, p.482-497, 2012. DOI: http://doi.org/10.1016/j.wasman.2011.11.008

RENOU, S.; GIVAUDAN, J. G.; POULAIN, S.; DIRASSOURYAN, F.; MOULIN, P.. Landfill leachate treatment: Review and opportunity. Journal of Hazardous Materials, v.150, n.3, p.468-493, 2008. DOI:

http://doi.org/10.1016/j.jhazmat.2007.09.077

SCANDELAI, A. P. J.; CARDOZO FILHO, L.; MARTINS, D.C. C.; FREITAS, T. K. F. S.; GARCIA, J. C.; TAVARES, C. R. G. Combined processes of ozonation and supercritical water oxidation for landfill leachate degradation. Waste Management, v.77, p.466-476, 2018. DOI: http://doi.org/10.1016/j.wasman.2018.04.031

SCARATTI, D.; BOLZON, A. L.; UNGERICHT, J. C.; SCARATTI, G.. Influência das condições hidroclimáticas no tratamento de esgoto sanitário por lagoas de estabilização de esgoto.

Evidência, v.14, n.2, 2014.
SCHEEREN, M. B.; KUNZ, A; STEINMETZ, L. R.; DRESSELER, V. L.. O processo ANAMMOX como alternativa para tratamento de águas residuárias, contendo alta concentração de nitrogênio. Revista Brasileira de Engenharia Agrícola e Ambiental, v.15, n.12, p.1289-1297, 2011. DOI: http://doi.org/10.1590/S1415-43662011001200011

SIZIRICI, B.; TANSEL, B.. Parametric fate and transport profiling for selective groundwater monitoring at closed landfills: A case study. Waste Management, v.38, n.1, p.263270, 2015. DOI:

http://doi.org.10.1016/j.wasman.2014.12.020

SMAHI, D.; HAMMOUMI, O. E.; FEKRI, A.. Assessment of the Impact of the Landfill on Groundwater Quality: A Case Study of the Mediouna Site, Casablanca, Morocco. Journal of Water Resource and Protection, v.5, n.4, p.440-445, 2013. DOI: http://doi.org/10.4236/iwarp.2013.54043

VON SPERLING, M.. Modelling of coliform removal in 186 facultative and maturation ponds around the world. Water Res., v.39, n.20, p.5261-5273, 2005. DOI: http://doi.org/10.1016/j.watres.2005.10.016

VON SPERLING, M... 3 ed. Belo Horizonte: UFMG, Lagoas de estabilização 2017.

WANG, L. S.; WEI, D. B.; WEI, J.; HU, H. Y.. Screening and estimating of toxicity formation with photobacterium bioassay during chlorine disinfection of wastewater. Journal of Hazardous Materials, v.141, n.1, p.289-294, 2007. DOI: http://doi.org/10.1016/j.jhazmat.2006.07.001

WATSON, K.; SHAW, G.; LEUSCH, F. D.; KNIGHT, N. L.. Chlorine disinfection by-products in wastewater effluent: Bioassay-based assessment of toxicological impact. Water Research, v.46, n.18, p.6069-6083, 2012. DOI: http://doi.org/10.1016/i.watres.2012.08.026

WIMMER, B.; HUBER-HUMER, M.; HRAD, M.; WATZINGER, A.. Stable isotope signatures for characterising the biological stability of landfilled municipal solid waste. Waste Management, v.33, n.10, p.2083-2090, 2013. DOI: http://doi.org/10.1016/j.wasman.2013.02.017

XIAO, S.; SONG, Y. H.; PENG, J.. Degradation of biologically treated landfill leachate by using electrochemical process combined with UV irradiation. Separation and Purification Technology, v.117, p.24-29, 2013. DOI: http://doi.org/10.1016/i.seppur.2013.04.024

YAO, Y.; GHOGARE, R.; DUNSMOOR, A.; DAVARITOUCHAEE, M.; CHEN, S.. Simultaneous ammonia stripping and anaerobic digestion for ef fi cient thermophilic conversion of dairy manure at high solids concentration. Energy, v.141, p.179-188, 2017. DOI: http://doi.org/10.1016/i.energy.2017.09.086

ZHANG, L.; TANG, C. J.; ZHENG, P.; JIN, R. C.. Anaerobic ammonium oxidation for treatment of ammonium-rich wastewaters. Journal of Zhejiang University SCIENCE B, v.9, n.5, p.416-426, 2008. DOI: http://doi.org/10.1631/jzus.B0710590

A CBPC - Companhia Brasileira de Produção Científica (CNPJ: 11.221.422/0001-03) detém os direitos materiais desta publicação. Os direitos referem-se à publicação do trabalho em qualquer parte do mundo, incluindo os direitos às renovações, expansões e disseminações da contribuição, bem como outros direitos subsidiários. Todos os trabalhos publicados eletronicamente poderão posteriormente ser publicados em coletâneas impressas sob coordenação da Sustenere Publishing, da Companhia Brasileira de Produção Científica e seus parceiros autorizados. Os (as) autores (as) preservam os direitos autorais, mas não têm permissão para a publicação da contribuição em outro meio, impresso ou digital, em português ou em tradução. 